\title{
O PLANO NACIONAL DE EDUCAÇÃO E A VALORIZAÇÃO DOCENTE: CONFLUÊNCIA DO DEBATE NACIONAL
}

Silke Weber*

\begin{abstract}
RESUMO: Este artigo apresenta ângulos do debate sobre a valorização docente. Retraça sentidos que foram se fixando nas políticas educacionais estabelecidas nos últimos 40 anos no contexto da luta em favor da democracia. Destaque é dado aos sentidos de valorização da docência defendidos em propostas da sociedade política e da sociedade civil, com ênfase naquelas incorporadas na legislação nacional. A análise é realizada em interlocução com interpretaçóes do debate acadêmico, principalmente, sobre a vinculação entre valorização do magistério, formação docente e qualidade da educação.
\end{abstract}

Palavras-chave: Valorização docente. Formação docente. Políticas educacionais. Qualidade da educação. PNE.

\section{The National Education Plan and teacher valorization: the national debate confuence}

ABSTRACT: This paper presents different angles of the debate on the status of the teaching profession in Brazil. It grasps the meanings that have been established in educational policies over the past 40 years, in the context of the struggle for democracy. Its focus lies on the proposals developed by political and civil societies, with a special emphasis on those that have been

\footnotetext{
* Universidade Federal de Pernambuco (UFPE), Programa de Pós-graduação em Sociologia, Recife, PE., Brasil. E-mail de contato: silke@elogica.com.br
} 
incorporated into national legislation. Therefore, the analysis mainly dwells on the academic debate concerning the links between the recognition/valorization of the teaching profession, teacher education and the quality of education.

Keywords: Valorization of teaching. Teacher education. Educational policies. Quality of education. PNE.

temática da valorização docente no âmbito da Educação Básica tem estado presente no debate educacional brasileiro 1 nas últimas décadas, ganhando especial destaque nas políticas governo, balizadas pelos Planos Nacionais de Educação (PNE).

Nos últimos 40 anos, todavia, os sentidos sobre a valorização do professor foram se definindo, ampliando e se fixando no embate das propostas formuladas por instâncias da sociedade civil e da sociedade política. Apresentar alguns ângulos desse debate constitui um dos propósitos deste texto, que também coloca em foco o protagonismo brasileiro a respeito da associação entre docência e qualidade da educação.

Papel relevante na análise é a distinção entre políticas de Estado e de governo, assim como a concepção de valorização profissional como reconhecimento da importância social de um trabalho específico. Nessa perspectiva, abordam-se inicialmente aspectos relacionados aos requerimentos para o exercício docente, formalizados em legislação de iniciativa governamental. $\mathrm{Na}$ esteira dessas questóes são mencionadas açóes da sociedade civil no tocante à formação docente e desdobramentos em sua relação com a sociedade política, caracterizadas pelo estabelecimento de acordos, de pactos, de políticas e de delimitação de sentidos quanto à visão de valorização docente.

O texto aponta, ainda, traços do debate a respeito do papel docente na efetivação da Educação Básica como direito social e na construção da melhoria da qualidade da educação pública. 


\section{A INICIATIVA GOVERNAMENTAL NA DELIMITAÇÃO DO EXERCÍCIO DOCENTE}

O Brasil, à semelhança de países do mundo ocidental, teve o exercício da docência nos anos iniciais de escolarização avocado pelo Estado (NÓVOA, 1991) ao se responsabilizar pela estruturação do sistema de ensino mediante criação de equipamentos escolares, regulação das formas de geri-los e definição dos conteúdos educacionais a serem ministrados. Sobretudo delineou requerimentos para o acesso e desempenho dos sujeitos sociais que teriam a tarefa inicial de contribuir para a inserção das novas geraçôes no mundo do conhecimento, da tecnologia, da cultura, das artes - os professores.

Em concomitância com o esforço contínuo para dar materialidade ao reconhecimento da obrigatoriedade do acesso ao curso primário (atualmente anos iniciais do ensino fundamental), inclusive mediante o recurso a açóes de caráter assistencial, o país buscou delimitar desde o início do século 20, os requerimentos necessários ao exercício da docência, ainda que restritos a açôes balizadas por uma política de caráter emergencial voltada para enfrentar a carência de professores face o contínuo crescimento da demanda por escolarização. Essa tônica emergencial vale ser dito, será alterada somente no final da década de 1980 quando a educação escolar passou a ser objeto importante da demanda da luta em favor da democracia, no contexto, entendida como direito social básico a ser assegurado com qualidade.

Com efeito, desde 1932 a questão da formação dos professores constituiu um dos fulcros do debate educacional que tecia críticas acerbadas sobre exercício docente desenvolvido sem preparação específica e sem formação geral e pedagógica. Incorporada pelo Manifesto dos Pioneiros da Educaçấo Nova que pleiteava a unidade de preparação especializada dos professores em cursos de nível superior, essa vertente, todavia, não conseguiu orientar o debate e as ações de formação do magistério nas décadas seguintes.

De fato, o caráter emergencial da política de formação de professores persistiu até os anos 1970, contraditoriamente nos marcos da Lei no 4.024/1961, referência da legislação educacional brasileira do 
século 20, implantada no âmbito do projeto desenvolvimentista que vai de par com os processos de industrialização e urbanização crescentes do país, que impunham demanda progressiva por escolarizaçáo em todos os níveis de ensino, a ser assegurada por escolas públicas e pela rede privada de ensino.

A referida Lei atribuiu ao curso normal "[...] a formação de professores, orientadores, supervisores e administradores escolares destinados ao ensino primário e o desenvolvimento dos conhecimentos relativos à educação da infância [...]", nos termos do art. 52. Entretanto, na linha de atuação emergencial do suprimento de quadros docentes, ao curso normal foram atribuídos dois graus de formação (art. 54): o de regente, equivalente ao nível ginasial de quatro séries, e o de professor primário, ao nível de colegial de três séries, garantindo ambos os títulos "igual direito a ingresso no magistério primário oficial ou particular" (art. 58). Ou seja, a lei promoveu a legitimação do exercício do magistério primário mediante a obtenção de um dos dois tipos de diplomas: o normal ginasial ou o de normal colegial, o que na prática contribuiu para diferenciar a formaçáo oferecida em escolas rurais - geralmente, unidocentes -, e em escolas urbanas, medida que está na raiz certamente das diferenças educacionais observadas ainda hoje entre as regióes do país.

Diante da forte expansão do curso primário realizada especialmente pelo setor público desde a década de 1960, não se pode negar que a principal tônica da legislação e das açôes governamentais no campo da educação básica tenha sido a formação do magistério, inclusive no que concerne à formação de professores para o próprio ensino normal. Esta, aliás, tanto poderia ocorrer em Faculdades de Filosofia, Ciências e Letras como em Institutos de Educaçáo, dicotomia que voltaria à tona no debate educacional por ocasiāo da sanção da Lei no 9.394/1996, conforme será adiante apontado.

Embora reconhecida a urgência da elevação progressiva do nível de titulação dos professores, a política de atendimento à carência de docentes continuou a ser a tônica nos anos 1970, conforme a Lei no 5.692/1971, promulgada em pleno regime autoritário: além de extinguir as escolas normais, ela remete a formação para o Magistério a uma das muitas habilitaçóes de nível médio (então $2^{\circ}$ grau), de caráter 
profissionalizante, bem como admite a formação de docentes para os anos finais do ensino fundamental (entâo denominado $1^{\circ}$ grau) e das disciplinas do ensino médio ( $2^{\circ} \mathrm{grau}$ ) em licenciatura curta (Art. 30b), e ainda arrola alternativas outras de formaçáo mediante a realização de estudos adicionais (Art.30).

Por outra parte, a lei estabeleceu também a remuneração docente por habilitação, considerando a maior qualificação obtida, sem distinção de graus escolares de atuação, conforme o (Art. 39), o que motivou mobilizaçóes frequentes de professores em todo país desde o final dos anos 1970, sob a égide da Confederaçáo dos Professores do Brasil (CPB), e delineou um dos sentidos presentes no debate a respeito da valorização docente. A recorrente inclusão dessa reivindicação caracterizou pautas de eventos de natureza corporativa desde 1974, sendo o Centro de Professores do Estado do Rio Grande do Sul (CEPERS) um protagonista destacado na sua formalização, relacionando-a a busca "pelo reconhecimento objetivo e concreto" da função social do magistério e "[...] do valor da própria educação como processo prioritário e essencial na formação e preparo do indivíduo para a vida comunitária e cultural [...]". (WEBER, 2003, p. 1143-1144)

Foi, entretanto, o caráter tecnicista da formação docente, com ênfase em instrumentos e métodos que passou a ser objeto de estudos específicos sobre a Lei e do debate social e acadêmico sobre a formação de professores que lhe deu sequência. (MELLO, 1983) A crítica à associação entre formação profissional e formação técnica demarcou um aprofundamento na compreensão da complexidade envolvida na docência, ganhando relevo a sua dimensão educativa e, em consequência, conduzindo à visão de professor como educador. No ambiente acadêmico, o tecnicismo foi obstáculo à consideraçáo da dimensão profissional da docência, temática que tem se estendido até os dias atuais em torno do formato do curso de Pedagogia e das características formativas das licenciaturas.

Não obstante, a discussão sobre a dimensão profissional da docência (LÜDKE, 1990) obteve saliência no debate a respeito da educação básica no âmbito do processo constituinte de 1987, no contexto da luta em favor da democracia. O reconhecimento do caráter profissional da docência associado à "valorização dos profissionais do ensino" findou 
por ser incorporado à Constituiçáo Federal de 1988 como um dos princípios "que devem servir de base ao ensino ministrado [...]". (Art. 206, inciso $\mathrm{V}$ )

A posição assumida pela Constituição Federal, dessa forma, desloca a preocupação da carência de docentes e enfrentamento do caráter seletivo do acesso escolar mediante açóes de natureza assistencial, para a qualidade do ensino ofertado nas escolas, e fundamenta a concepção de educaçáo escolar como um direito social básico, consubstanciado no direito de aprender de modo sistemático conhecimento, arte, cultura, tecnologia, produzidos ao longo da história humana.

A valorização dos profissionais da educação escolar, como formulada no inciso V, do Art. 206, na Emenda Constitucional no 53, de 19 de dezembro de 2006, remete não somente à remuneração segundo a habilitação, como dispôs a Lei no 5.692/1971, mas inclui as condiçóes de trabalho "[...] na forma de planos de carreira para o magistério público, com piso salarial profissional e com ingresso exclusivamente por concurso público de provas e títulos [...]”. Alarga-se, dessa forma, a concepção de valorização da docência mediante a articulação orgânica entre formação, condições de trabalho e remuneração compatível com o seu reconhecimento social, organizando demandas oriundas do debate sobre educação, que teve como protagonista o Fórum Nacional em Defesa da Educação Pública.

Nessa perspectiva, a regulamentação da Constituição Federal, no que se refere à educação realizada segundo os termos da Lei no 9.394/1996, ao demarcar a natureza dos vínculos entre escolas e professores na tarefa de promover "[...] o pleno desenvolvimento do educando, seu preparo para o exercício da cidadania e a sua qualificação para o trabalho [...]" (Art.2\%), explicita o núcleo de preparação docente e não somente o nível de titulação requerido a ser obtido em curso de licenciatura, de graduação plena (Art. 62).

Diferentemente do que pleiteavam entidades da sociedade civil envolvidas com a temática da qualidade da educação - princípio constitucional (Art. 206, inciso VII) - e da valorizaçáo docente, tal formação, em curso de licenciatura de graduação plena, poderia ser realizada em universidades ou em um novo espaço - os institutos superiores 
de educação -, o que suscitou polêmica durante mais de uma década, polarizada em torno do lugar do curso de Pedagogia na formação de professores.

Mencionar aspectos desse debate sob a perspectiva da Teoria do Discurso (LACLAU; MOUFFE, 1985; HOWARD, 1995; TORFING, 1999) permitirá retraçar os elementos que foram sendo aglutinados em momentos relacionais específicos e que conduziram à condensação dos sentidos de qualidade da educação e de valorização da docência em legislação ou em políticas públicas, concebidas como arranjos conjunturais das lutas e negociaçôes que movem as diferentes esferas da vida social e repercutem na discussão sobre a docência.

\section{A SOCIEDADE CIVIL E A DEFINIÇÃO DE POLÍTICAS EDUCACIONAIS DE FORMAÇÃO DOCENTE}

Não obstante a conjuntura de repressão aos direitos políticos e de cidadania, ao longo do período autoritário alguns setores sociais se mobilizaram intensamente em torno de suas reivindicaçóes e criaram ou reativaram entidades que passaram a ser atuantes na sistematização das demandas e no aprofundamento do debate de seus problemas específicos, em especial nas áreas da saúde e da educação. $\mathrm{Na}$ área educacional, o debate sobre a relação entre democracia e educação escolar foi ampliado, tendo como fulcro a superação da seletividade no acesso à escolaridade obrigatória propugnada desde o Manifesto dos Pioneiros de 1932, conforme assinalado, bem como as formas de assegurar ao aluno uma trajetória educacional de sucesso em um sistema escolar organizado de forma democrática. Tal debate realizado no contexto dos estudos desenvolvidos, em 1970, por Althusser e por Bourdieu e Passeron a respeito da dimensão da reprodução das relaçóes sociais e da cultura contida na ação escolar, sofreu em seguida uma inflexão sob a influência da leitura de Gramsci, que atentava para a dimensão transformadora da educação, colocando em relevo a discussão sobre a qualidade da educação escolar socialmente referenciada e o papel do professorado na sua construção.

Apropriada e veiculada pela produçáo acadêmica oriunda da pós-graduação sobre a realidade do país em suas diferentes dimensôes, 
a perspectiva gramsciana deu substrato na década de 1980 (SAVIANI, 1983) à visão de escola como instância orgânica dos segmentos subalternos na luta pela construção de uma nova sociedade, e ao professor atribuiu o papel de educador, cuja tarefa profissional deveria associar à atividade educativa, a ação organizativa da sociedade.

$\mathrm{Na}$ trilha desse debate ganhou realce o tema da formação do educador (como passou a ser denominado o professor), e também foi criado o Movimento em Prol da Formação do Educador (1978), que forneceu os fundamentos para a constituição da Associação Nacional pela Formação dos Profissionais da Educação (Anfope) em 1991. Esta entidade, ao lado da Confederaçáo Nacional dos Trabalhadores da Educação (CNTE), do Centro de Estudos Educação e Sociedade (Cedes) e da Associação Nacional da Educação (Anped), entre outras, vêm desde então assumindo importante protagonismo no debate e na definição das políticas educacionais, inclusive na formulação dos Planos Nacionais de Educação (PNE) de 2001 e de 2014.

Vale reportar algumas das iniciativas que têm dado destaque ao professorado e contaram com a presença ativa daquelas e de outras entidades, cujas contribuiçóes conformam hoje, de algum modo, políticas educacionais tanto de Estado como de Governo, apropriadas ou reinterpretadas notadamente pela esfera federal, sobretudo a partir de meados dos anos 1990. Tais contribuiçôes não ficam restritas a conteúdos que, em geral, são perpassados pelo debate acadêmico nacional e internacional em curso, mas influenciam também processos de formulação e execução de políticas educacionais que tendem a ganhar caráter participativo, a exemplo da elaboração dos Planos Nacionais de Educação de 2001 e de 2014, formulados mediante a realização, respectivamente, de Congressos e de Conferências locais e de caráter nacional.

A reformulação do curso de Pedagogia (FRANCO; LIBÂNEO; PIMENTA, 2007; FREITAS, 2002; GATTI; BARRETO, 2009) foi uma das propostas que perpassaram o debate sobre formação docente, na expectativa de dotá-lo de uma base comum nacional fundada na docência e norteado por "sólida formaçâo teórica", observando "unidade entre teoria e prática”, com destaque para "a pesquisa como meio de produção do conhecimento e de intervenção na prática”; gestão democrática como instrumento de luta contra a gestão autoritária da escola; 
"compromisso social e ético, com ênfase na concepção sociohistórica de educação; trabalho coletivo e interdisciplinar"; articulação entre formação inicial e continuada, aspectos esses que findaram por constituir referenciais das Diretrizes Nacionais Curriculares (DCN) para a Formação de Professores da Educação Básica em nível superior, formuladas pelo Conselho Nacional de Educação, em 2001. Esta visão não obteve consenso, entretanto, persistindo até a atualidade a contraposição base comum nacional e diretrizes curriculares nacionais.

A base comum nacional foi concebida como "[...] instrumento de luta e de resistência contra a degradação do magistério, permitindo a organização e reivindicação de políticas de profissionalização que garantam a igualdade de condiçóes de formação [...]". A base comum nacional constituiria, segundo as entidades envolvidas, no elemento unificador da profissão, distinta da ideia de formação comum que caracterizaria as diretrizes curriculares nacionais para a formação de professores. As diretrizes então estabelecidas pelo CNE seriam vistas como orientadas para o desenvolvimento de competências, visão que teria resgatado a ênfase na dimensão técnica da formação docente, tão criticada desde a sanção da Lei no 5.692 de 1971.

A Confederação Nacional dos Trabalhadores da Educação (CNTE), oriunda da CPB, por sua vez, desde o final de 1980 e início de 1990, formulava a concepção de docente como trabalhador em educação, concentrando as suas reivindicaçóes em torno de condições de trabalho adequadas e de salário condigno. Tal postura esclarece a razão pela qual somente a partir de 1993 a CNTE acrescenta à sua luta pela definição de piso salarial nacional, o aperfeiçoamento contínuo do professorado, tanto em cursos regulares de formaçáo como de oportunidades sistemáticas de capacitação, reforçando, assim, a consideração da dimensão educativa da docência pleiteada pela Anfope e já assumida também por outras entidades e políticas de governo.

O alargamento do sentido de valorização do docente ou do magistério, delineado no debate, social ganhou relevo ao longo do processo de formulação do Plano Decenal Educação para Todos - 1993-2002, elaborado no contexto do reconhecimento da importância de fatores intraescolares na aprendizagem escolar, analisados exaustivamente na produção acadêmica do período. A iniciativa coordenada pelo Ministério 
da Educação (MEC) para dar materialidade ao compromisso assumido pelo Brasil como subscritor da Declaração de Jomtien, em 1990, contou com o apoio da União dos Dirigentes Municipais de Ensino (Undime) e do Conselho Nacional de Secretários de Educação (Consed), entidades da sociedade política criadas na segunda metade dos anos 1980, constituídas por vários integrantes de quadros ligados à instância acadêmica.

Nesse processo, foi destacado o caráter mediador da prática pedagógica na relação entre sociedade e educação, assim como foi resgatado o lugar central do professorado na aprendizagem dos alunos, visão que impulsionou a criação do Fórum Permanente de Valorização do Magistério e da Qualidade da Educação.

A celebração do Pacto de Valorização do Magistério e da Qualidade da Educação, em outubro de 1994, e a atuação do Fórum Permanente ensejaram a definição de parâmetros para o exercício da docência. A desvalorização social do magistério, então associada à baixa autoestima, engendrada pelas precárias condiçóes de trabalho, por baixos salários e pouca clareza quanto aos requisitos de formação, deu substrato à formulação das Referências Nacionais para a carreira do magistério e ensino de qualidade, em agosto de 1995, sendo mais adiante incorporada às Diretrizes para os Planos de Carreira e Remuneração, definidas pela Câmara de Educação Básica do Conselho Nacional de Educação, em 1997.

O Pacto de Valorização do Magistério pretendia fundamentar políticas de longo prazo para a profissionalização docente, e nesse sentido estabeleceu cinco linhas de ação, três das quais voltadas para a formação do magistério: estudos para esclarecer o papel das instituiçóes na formação inicial e continuada; formação progressiva em nível superior com revisão simultânea dos conteúdos das licenciaturas do sistema de formação de nível médio e de formação continuada, e acompanhamento do trabalho docente por meio de assistência técnico-científica, intercâmbio e cooperação.

Embora a valorização do magistério tenha passado a constituir uma das prioridades do Consed, em 1995, foi no âmbito do Fórum Permanente de Valorização do Magistério e da Qualidade da Educação, convocado em meados daquele ano pelo MEC, que foram estabelecidas 
referências básicas nacionais para a formulação de estatutos, carreira, salários, formação de professores, representando momento histórico de confluência do debate sobre a valorização docente que até então contrapunha salário e condiçôes de trabalho a formação docente.

Ganham destaque nessa ocasião, a formação inicial e a continuada do professorado, o reconhecimento da dimensão pedagógica das horas-atividade, o estabelecimento de número máximo de alunos por sala de aula, a definição da jornada de trabalho de 40 horas como horizonte a ser perseguido pelas esferas estaduais e municipais, a fixação de piso salarial nacional. A não aceitação pelo MEC destas duas últimas referências, no entanto, motivou a retirada da CNTE do Fórum, favorecendo que o protagonismo do debate e de iniciativas em relação ao magistério da Educação Básica, até então liderado por entidades da sociedade civil, passasse a ser assumido pelo Ministério de Educação, que incorporou ou desconsiderou propostas reiteradamente afirmadas no debate acadêmico e social.

\section{O MEC NA DIREÇÃO DA POLÍTICA EDUCACIONAL}

Desde a promulgação da Constituição Federal em 1988 estava estabelecido o lastro orientador das políticas de valorização dos profissionais da educação, valendo destacar, entre outros aspectos, o resgate do concurso público como forma única de recrutamento de pessoal docente pelas esferas governamentais. A confirmação desta prescrição nas constituiçóes estaduais e leis orgânicas municipais ensejou a definição de requisitos mínimos de formação e de competências para o exercício docente, bem como o estabelecimento de diretrizes para a elaboração de planos de carreira e remuneração.

A criação do Fundo de Manutenção e Desenvolvimento do Ensino Fundamental e de Valorização do Magistério (Fundef) pela Emenda Constitucional 14/1996 e da Lei no 9.424/1996 dela decorrente, no âmbito do debate sobre o não cumprimento da alocação dos recursos financeiros obrigatoriamente vinculados à educação fundamental, pelas três esferas de poder, foi um passo significativo na política de valorização dos profissionais da educação dado que procurou equalizar 
os custos mínimos por aluno entre estados e seus municípios; determinou a criação de plano de cargos e carreira para os docentes; estabeleceu prazo para a formação de professores leigos nas diferentes acepçóes que a expressão envolve, e instituiu mecanismos de controle social da aplicação do Fundef. Tais medidas, todavia, suscitaram resistência por parte das entidades envolvidas no debate educacional em razão da prioridade dada à dimensão financeira, como também produziram impacto nos sistemas de ensino, nas instituiçóes formadoras e na situação profissional do professorado, que se tornou importante agente de pressão para a sua efetivação.

Mas foi a LDB de 1996 que provocaria a mobilização da sociedade para o cumprimento do seu Art. $87 \$ 1^{\circ}$, segundo o qual a Uniáo, no prazo de um ano após a sua promulgação, deveria encaminhar ao Congresso Nacional o Plano Nacional de Educação (PNE), com diretrizes e metas para os 10 anos seguintes, em sintonia com a Declaração Mundial sobre Educação para Todos de 1990. A elaboração deste Plano, a ser transformado pela primeira vez no país em lei, movimentou as diferentes entidades envolvidas com a questáo educacional, que conseguiram submeter à apreciação do Congresso Nacional texto formulado e consolidado nos I e II Congresso Nacional de Educação (Coned), denominado PNE - Proposta da Sociedade Brasileira (PL no 4.155/1998). O MEC por sua vez, apresentou projeto de sua iniciativa ( $\mathrm{PL} \mathrm{n}^{\circ} 4.173 / 1998$ ), apensado à primeira versão do PNE, motivando debates acirrados tanto no Congresso como entre as entidades que continuavam a disputar com o MEC a organização do debate sobre educação.

Em ambos os projetos de lei, a questão da valorizaçáo docente abarcava duas importantes reivindicaçóes dos professores da Educação Básica e das suas entidades representativas: piso salarial nacional e plano de carreira. O estabelecimento do Piso Salarial Nacional findou ganhando legislação específica por intermédio da Lei no 11.738, de 16 de julho de 2008, na esteira do Plano de Desenvolvimento da Educação (PDE) formulado em 2007.

Pretendendo superar a visão fragmentada das políticas educacionais, e sem avaliar formalmente a execução do Plano Nacional de Educação de 2001 (Lei no 10.172, de 09 de janeiro de 2001), o PDE (Decreto no 6.094, de 24 de abril de 2007) - Plano de Metas Compromisso 
Todos pela Educação - propôs uma visão sistêmica de educação escolar, segundo a qual questóes de atendimento, acompanhamento e controle social passavam a ser articuladas organicamente com vistas a promover novos padrôes de qualidade da açáo educativa formal e a redimensionar as açôes entre as instâncias federativas.

A Avaliação de Campo proposta pelo MEC, como principal instrumento de acompanhamento da execução das políticas educacionais, teve a formação inicial e continuada dos professores e dos profissionais de apoio como uma das dimensóes focalizadas, na perspectiva de operar intervenções tendo o Índice de Desenvolvimento da Educação (Ideb) como principal baliza das metas estabelecidas.

Além de conter dimensão regulatória importante e de visar a interdependência dos fatores relacionados à construção de patamares de qualidade, o papel do docente se tornou central e sua valorização incluiu a concentração da jornada de trabalho em uma única escola e o recebimento de remuneração condizente mediante a fixação de piso salarial nacional.

\section{PROCESSO DE FIXAÇÃO DE SENTIDOS DA VALORIZAÇÃO DOCENTE}

Se desde a promulgação da Constituição Federal de 1988 o princípio da valorização docente é reconhecido e utilizado como referência para o estabelecimento de políticas educacionais voltadas para o professorado, o sentido que o abarca, na atualidade, aprofunda a articulação de demandas históricas de condições de trabalho e de formação inicial e continuada. (ALVES, 1992; CUNHA, 1999; GATTI; BARRETO, 2009; GATTI; BARRETO; ANDRE, 2011)

Deve ser registrado, aliás, que no âmbito da vigência do PDE o MEC tem-se mostrado proativo em relaçáo à tarefa de oferecer e impulsionar a formação inicial e continuada de professores, mediante a instituição da Política Nacional de Formação dos Profissionais do Magistério da Educação Básica, coordenada pela Diretoria de Formação de Professores da Educação Básica, criada na Capes para este fim. Tal 
política foi instituída mediante o Decreto no 6.755, de 29 de janeiro de 2009 , tendo como um dos seus princípios o reconhecimento da "[...] importância do docente no processo educativo da escola e da sua valorização profissional [...]" a ser "[...] traduzida em políticas permanentes de estímulo à sua profissionalização, à jornada única, à progressão na carreira, à formação continuada, à dedicação exclusiva ao magistério, à melhoria das condições de remuneração e à garantia de condiçôes dignas de trabalho [...]" (Art. 20, inciso VIII). Em suma, este princípio de política sintetiza o sentido que ao longo dos anos foi sendo delineado no debate social e acadêmico como valorização docente, que associa facetas diversas das condiçóes de trabalho e de formaçáo, tal como abordado em 28 metas relacionadas à valorização do magistério, inscritas no PNE de 2001.

Consistente com tal princípio, a Diretoria de Formação de Professores da Educação Básica da Capes tem o objetivo de induzir a formação inicial de professores para a Educação Básica, em articulação com o Plano Nacional de Formação de Professores da Educação Básica (Parfor), e organizar programas voltados para a valorização do magistério. Suas tônicas de ação se pautam pela formação de qualidade, integração entre pós-graduação, formação de professores e escola básica e produção de conhecimento, e correspondem ao debate educacional dos últimos 40 anos que tem integrado as dimensóes relacionadas a trabalho e formação no sentido do que hoje é referido como valorização docente.

No PNE 2001-2010, aliás, formação de professores e valorização do magistério, objeto do tópico 10 , eram apresentadas como prioridades, com ênfase na formação inicial e continuada de professores e na valorização definida como "garantia das condiçóes adequadas de trabalho". Esta abrange não somente salário digno, piso salarial e carreira de magistério, mas também dimensóes condicionantes da qualidade da ação docente tais que tempo para estudo e preparação de aulas, aspectos gestados no debate social e acadêmico das décadas precedentes, e que no texto da Lei se tornam conteúdo das diretrizes para a efetivação de ambas facetas - formação e valorização.

As 28 metas estabelecidas, não obstante, eram genéricas e, portanto, de difícil acompanhamento, fato que frequentemente foi imputado à falta de previsão de custos e indefinição do papel da União 
na efetivação das prioridades selecionadas. Essa constatação repercutiu na elaboração do PNE 2014-2024, construído em torno da concepção de educação de qualidade como direito social básico, cuja materialização requer ação coordenada e articulada dos sistemas de ensino e destinação de recursos com foco determinado.

Quanto à formação docente, convém lembrar que constam como diretrizes do PNE 2001 orientaçóes que vinham sendo discutidas no âmbito acadêmico e social visando, principalmente, a sedimentação da base comum nacional e reivindicaçóes a ela associadas. Tal fato indica a persistência da disputa pela fixaçâo de determinados sentidos que possam dar materialidade à especificidade da ação docente a ser desenvolvida na perspectiva da educação como direito social básico e condição de exercício da cidadania.

Tônica semelhante atravessa o PNE 2014-2024, elaborado em um processo de discussão capitaneado por delegados eleitos para as conferências de educação realizadas nos níveis locais, estaduais, regionais e nacional e cujo debate legislativo durante quase três anos se concentrou, principalmente, em torno do percentual do PIB a ser aplicado à educação. Entretanto, diferentemente do primeiro Plano tornado lei no país, o Plano Nacional de Educação que recobre o decênio 2014-2024, fixou tão somente 20 metas e respectivas estratégias para a sua consecução. Contou para a sua formulação com um novo protagonista: o Fórum Nacional de Educação, conforme deliberação da Conae de 2010, instância a qual é atribuída a coordenação do monitoramento da execução do Plano em vigor, com participação do $\mathrm{MEC}, \mathrm{CNE}$, Comissão de Educação da Câmara dos Deputados e Comissão de Educação, Cultura e Esportes do Senado Federal.

Importa salientar que dentre as 20 metas estabelecidas, quatro delas $(15,16,17$ e 18) têm como alvo o professorado da educação básica da rede pública: a meta 15 estabelece que todos os professores, ao final dos 10 anos recobertos pelo Plano, terão completado "[...] formação específica em nível superior obtida em curso de licenciatura na área de conhecimento em que atuam [...]"; a meta 16, determina que $50 \%$ dos professores da educação básica obtenham formação pós-graduada durante o período de vigência do Plano e que a todos os professores, 
nesse mesmo período, sejam asseguradas oportunidades de formação continuada.

A valorização do professor da educação básica é expressa na meta 17 que prevê a aproximação de sua remuneração à dos demais profissionais com escolaridade equivalente, até o $6^{\circ}$ ano de vigência do atual PNE, pleito que foi recorrente no CEPERS nas mobilizaçóes de meados de 1970. Por fim, a meta 18 objetiva "[...] assegurar planos de carreira para os professores da educaçáo básica pública de todos os sistemas de ensino $[\ldots]$ ".

Tal como foi possível observar, o debate sobre a valorização docente polarizada, incialmente, entre ação educativa e atividade do mundo do trabalho foi incorporando novos elementos que findaram por fazer confluir os dois sentidos para ação educativa de caráter profissional, que requer formação longa, em nível superior, e aperfeiçoamento contínuo do seu fazer educacional em condiçôes de trabalho adequadas ao exercício de sua tarefa educacional.

\section{CONSIDERAÇÕES GERAIS}

Tem-se, assim, o reconhecimento de que a efetivaçáo da valorização docente implica em um conjunto articulado de políticas de formação inicial, formação continuada (a ser executada em associação com as diversas esferas de governo e as instâncias formadoras) e políticas de carreira, remuneração, condiçóes de trabalho, de responsabilidade dos sistemas de ensino, que requerem simultaneidade de ação, para que possam produzir melhorias substantivas no sistema educacional do país.

Como visto, o debate capitaneado nos últimos 40 anos por entidades da sociedade civil, por organizaçóes da sociedade política, inclusive as que congregam secretarias estaduais e municipais de educação, e instâncias do MEC, permitiu não somente identificar o aspecto multifacetado da qualidade da educação escolar, mas, sobretudo, alçá-la à política de Estado.

A Resolução CNE/CP no 2 de $1^{\circ}$ de julho de 2015 estabelecendo "Diretrizes Curriculares Nacionais para a formação inicial em 
nível superior (cursos de licenciatura, Programas e cursos de formação pedagógica para graduandos) e cursos de segunda licenciatura e formação continuada", pode dessa forma, ser concebida como síntese do longo percurso de fixação de sentidos que associou dimensão educativa e profissional da docência e a relacionou de forma orgânica à valorização do magistério.

Ao longo do debate e disputa de sentidos sobre educação escolar aqui tematizado, consolidou-se a concepção de docência como "[...] ação educativa e processo pedagógico intencional e metódico [...]" cujo exercício requer "uma sólida formação científica e cultural inerente ao ensinar e ao aprender" (CNE, Art. $2^{\circ}, \$ 1^{\circ}$ ), ou seja, uma formação específica direcionada "[...] à melhoria da qualidade social da educação e à valorização profissional [...]". O reconhecimento desta tarefa educacional, a ser assegurada "[...] em regime de colaboração pelos entes federados nos respectivos sistemas de ensino [...]" e desenvolvida pelas instituiçóes formativas credenciadas $\left(\mathrm{CNE}\right.$, Art. $\left.3^{\circ}, \$ 3^{\circ}\right)$, constitui, certamente, um processo que poderá contribuir para tornar a educação escolar prioridade nacional.

A formação específica para o magistério e a valorização profissional tornaram-se aspectos de um mesmo processo de socialização e exercício profissional e de materialização da educação como direito social básico. Esta concepção é consolidada na proposta de Resolução do CNE, capítulo VII, que igualmente estabelece diretrizes para a valorização docente. Esta é assim reafirmada "como dimensão constitutiva e constituinte da formação inicial e continuada", que inclui dentre outros aspectos, planos de cargos e salário e condiçóes que assegurem jornada de trabalho em dedicação exclusiva ou tempo integral, a ser cumprida em uma única escola e destinação de $1 / 3$ da carga horária a atividades relacionadas à docência.

A pressão e participação das entidades da sociedade que souberam explorar determinadas oportunidades políticas conjunturais deram mostras de que foi possível incorporar algumas de suas propostas nas políticas públicas educacionais, caso, por exemplo, da delimitação do sentido sobre valorização docente. 


\section{REFERÊNCIAS}

ALVES, N. (Org.). Formação de professores: pensar e fazer. São Paulo: Cortez, 1992.

CUNHA, M. I. Profissão docente: contradição e perspectivas. In: VEIGA, I. P.; CUNHA, M. I. (Org.). Desmistificando a profissão do magistério. Campinas: Papirus, 1999, p.127-147.

BRASIL. Lei no 4.024, de 20 de dezembro de 1961. Fixa as diretrizes e bases da educação nacional. Diário Oficial da Uniâo, Brasília, DF., 27 dez 1961. Disponível em: <https://www.planalto.gov.br/ccivil 03/leis/14024.htm>.

. Lei no 5.692, de 11 de agosto de 1971. Lei de Diretrizes de Bases. Fixa diretrizes e bases para o ensino de $1^{\circ} \mathrm{e} 2^{\circ}$ graus, e dá outras providências. Diário Oficial da Uniáo, Brasília, DF., 12 ago 1971. Disponível em: <http://www2. camara.leg.br/legin/fed/lei/1970-1979/lei-5692-11-agosto-1971-357752-publicacaooriginal-1-pl.html .

. Constituição (1988). Constituiçáo da República Federativa do Brasil. Brasília: Senado Federal, 1988.

. Emenda Constitucional no 14, de 12 de setembro de 1996. Modifica os arts. 34, 208, 211 e 212 da Constituição Federal e dá nova redação ao art. 60 do Ato das Disposiçóes Constitucionais Transitórias. Diário Oficial da Uniáo, Brasília, DF, 13 set 1996. Disponível em: <https://www.planalto.gov. br/ccivil 03/constituicao/emendas/emc/emc14.htm >.

. Emenda Constitucional no 53, de 19 de dezembro de 2006. Dá nova redação aos arts. $7^{\circ}, 23,30,206,211$ e 212 da Constituição Federal e ao art 60 do Ato das Disposiçôes Constitucionais Transitórias. Diário Oficial da União, Brasília, DF., 20 dez 2006. Disponível em: <https://www.planalto.gov.br/ccivil 03/constituicao/emendas/emc/emc53.htm $>$.

. Lei no 11.738 , de 16 de julho de 2008. Regulamenta a alínea "e" do inciso III do caput do art. 60 do Ato das Disposiçóes Constitucionais Transitórias, para instituir o piso salarial profissional nacional para os profissionais do magistério público da educação básica. Diário Oficial da União, Brasília, DF., 17 jul 2008. Disponível em: <https://www.planalto.gov.br/ccivil 03/ ato20072010/2008/lei/l11738.htm>.

. Lei n o 13.005, de 25 de junho de 2014. Aprova o Plano Nacional de Educação - PNE e dá outras providências. Diário Oficial da Uniáo, Brasília, 
DF., 26 jun 2014 - edição extra. Disponível em: <https://www.planalto.gov.br/ ccivil_03/_ato2011-2014/2014/lei/l13005.htm>.

BRASIL. Câmara dos Deputados. Projeto de Lei no 4.155, de 10 de fevereiro de 1998. Aprova o Plano Nacional de Educaçáo. Diário da Câmara dos Deputados, Brasília, DF., 12 mar 1998. Disponível em <http://imagem.camara.gov.br/ Imagem/d/pdf/DCD12MAR1998.pdf\#page $=89>$.

. Câmara dos Deputados. Projeto de Lei no 4.173, de 11 de fevereiro de 1998. Apensado ao PL no 4.155. Aprova o Plano Nacional de Educaçáo, de 10 de fevereiro de 1998. Diário da Câmara dos Deputados, Brasília, DF., 12 mar 1998. Disponível em <http://imagem.camara.gov.br/Imagem/d/pdf/ DCD12MAR1998.pdf\#page $=122>$.

. Ministério da Educaçáo. Fórum Permanente de Valorização para o Magistério: diretrizes de carreira. MEC: Brasília, 1995.

. Ministério da Educação. Lei no 9.424, de 24 de dezembro de 1996. Dispõe sobre o Fundo de Manutenção e Desenvolvimento do Ensino Fundamental e da Valorização do Magistério, na forma prevista no art. $60 \$ 7^{\circ}$, do Ato das Disposiçôes Constitucionais Transitórias e dá outras providências. Diário Oficial da Uniáo, Brasília, DF., 26 dez 1996. Disponível em: <https://www. planalto.gov.br/ccivil_03/leis/19424.htm>.

. Ministério da Educaçáo. Lei no 10.172, de 09 de janeiro de 2001. Aprova o Plano Nacional de Educação e dá outras providências. Diário Oficial da Uniáo, Brasília, DF., 10 jan 2001. Disponível em: <https://www.planalto. gov.br/ccivil 03/leis/leis 2001/110172.htm>.

. Ministério da Educaçáo. Decreto no 6.094, de 24 de abril de 2007. Dispôe sobre a implementação do Plano de Metas Compromisso Todos pela Educação, pela União Federal, em regime de colaboração com Municípios, Distrito Federal e Estados, e a participação das famílias e comunidade mediante programas e açôes de assistência técnica visando a mobilização social pela melhoria da qualidade da educação básica. Diário Oficial da Uniáo, Brasília, DF., 25 abr 2007. Disponível em: <https://www.planalto.gov.br/ccivil 03/ ato20072010/2007/decreto/d6094.htm>

. Ministério da Educação. Decreto no 6755, de 29 de janeiro de 2009. Institui a Política Nacional de Formaçâo de Profissionais do Magistério da Educação Básica, disciplina a atuação da Coordenação de Aperfeiçoamento de Pessoal de Nível Superior - CAPES no fomento a programas de formação inicial e continuada, e dá outras providências. Diário Oficial da Uniáo, Brasília, DF., 
30 jan 2009. Disponível em: <https://www.planalto.gov.br/ccivil 03/ ato20072010/2009/decreto/d6755.htm>.

BRASIL. Ministério da Educação e Cultura. Lei no 7.044, de 18.10.1982. Altera dispositivos da Lei no 5.692, de 11 de agosto de 1971, referente à profissionalização do ensino de $2^{\circ}$ grau. Diário Oficial da Uniáo, Brasília, DF., 19 out 1981. Disponível em: <https://www.planalto.gov.br/ccivil 03/leis/l7044. htm>.

. Ministério da Educação e Cultura. Plano Decenal de Educação para Todos-1993-2002. Brasília: MEC, 1993.

. Ministério da Educaçáo e do Desporto. Lei no 9.394, de 20 de dezembro de 1996. Estabelece as diretrizes e bases da educaçáo nacional. Diário Oficial da Uniáo, Brasília, DF., 23 dez 1996. Disponível em: < https://www. planalto.gov.br/ccivil 03/Leis/L9394.htm>.

MINISTÉRIO DA EDUCAÇÃO. Portaria no 1.407 , de 14 de dezembro de 2010. Institui o Fórum Nacional de Educação - FNE. Diário Oficial da União, Brasília, DF., 6 dez 2010. Disponível em: <http://fne.mec.gov.br/images/doc/ Portaria1407.pdf>.

. Conselho Nacional de Educação. Parecer CNE/CP no 9, de 08 de maio de 2001. Diretrizes Curriculares Nacionais para a Formação de Professores de Educação Básica, em nível superior, curso de Licenciatura, graduaçáo plena. Diário Oficial da Uniáo, Brasília, DF., 18 jan 2002. Disponível em: <http:// portal.mec.gov.br/cne/arquivos/pdf/009.pdfs.

. Conselho Nacional de Educação. Resolução CNE/CP no 2 de $1^{\circ}$ de julho de 2015. Diretrizes Curriculares Nacionais para a formação inicial em nível superior (cursos de licenciatura, Programas e cursos de formação pedagógica para graduandos) e cursos de segunda licenciatura e formação continuada. Diário Oficial da Uniáo, Brasília, DF., 02 jul 2015. Disponível em: $<\underline{\text { http://portal. }}$ mec.gov.br/index.php?option=com docman\&view=download\&alias=17719res-cne-cp-002-03072015\&category slug=julho-2015-pdf\&Itemid=30192>.

FRANCO, M. A. S.; LIBÂNEO, J. C.; PIMENTA, S. G. Elementos para a formulação de diretrizes curriculares para cursos de pedagogia. Cadernos de Pesquisa (Fundaçẫo Carlos Chagas), v. 37, p. 63-97, 2007.

FREITAS, H. C. L. Formação de Professores no Brasil: 10 anos de embates entre projetos de formação. Educ. Soc., Campinas, v. 23, n. 80, p. 137-168, 2002.

GATTI, B.; BARRETO, E. S. Professores do Brasil: impasses e desafios. Brasília, DF: UNESCO, 2009. 
GATTI, B. A.; BARRETO, E. S.; ANDRE, M. E. D. A. Politicas docentes no Brasil: um estado da arte. Brasília, DF: Unesco, 2011.

HOWARTH. D. Discourse Theory. In: MARSH, D.; SOKER, G. Theory and methods in political science. New York: Saint Martin's, 1995.

LACLAU, E.; MOUFFE, C. Hegemony and socialist strategies. London: Verso, 1985.

LUDKE, M. O educador: um profissional? In: CANDAU, V. (Org.). Rumo a uma nova didática. Petrópolis: Vozes, p. 64-73, 1990.

MELLO, G. M. Magistério de Primeiro Grau: da competência técnica ao compromisso político. 10a. ed. São Paulo: Cortez Editora, 1993.

NÓVOA, A. Para o estudo sócio-histórico da gênese e desenvolvimento da profissão docente. Teoria e Sociedade, n.1, p.109-139, 1991.

SAVIANI, D. Competência Política e Compromisso Técnico. Educ. Soc., v. 5, p. 111-143, 1983.

TORFING, J. New Theories of discourse: Laclau, Mouffe and Zizek. Oxford: Blackwell Publishers, 1999.

WEBER, S. Profissionalização docente e políticas públicas no Brasil. Educ. Soc., Campinas, v. 24, n. 85, p. 1125-1154, 2003.

Recebido em 01 de junho de 2015.

Aprovado em 15 de setembro de 2015.

DOI: http://dx.doi.org/10.1590/CC0101-32622015150375 